\title{
A FAILURE PROCESS OF STEEL-CONCRETE COMPOSITE BRIDHE DECK SUBJECTED TO REPETITIVE MOVING LOADS IN THREE- DIMENSIONAL NONLINEAR FE ANALYSIS
}

\author{
Chikako FUJIYAMA ${ }^{1}$, Toshio MATSUMURA ${ }^{2}$ and Takehiro TAKASUKA ${ }^{2}$ \\ ${ }^{1}$ Member of JSCE, Associate Prof., Dept. of Civil and Environmental Eng., Hosei University \\ (Ichigaya-tamachi 2-33, Shinjuku-ku, Tokyo 162-0843, Japan) \\ E-mail: fujiyama@hosei.ac.jp \\ ${ }^{2}$ Member of JSCE, Japan Bridge Association, Engineering Committee, Subcommittee on Bridge Slab Engineering \\ (Nishi-shinbashi 1-6-11, Minato-ku, Tokyo 105-0003, Japan)
}

\begin{abstract}
This paper shows the failure mechanism of steel-concrete composite bridge deck having studs and ribs subjected to repetitive moving loads. Three-dimensional nonlinear FE analysis was used. First, the property of interface element between steel and concrete was identified by sensitivity analyses. Next, the progress of strains of concrete and steel elements obtained in simulation were examined throughout all the loading programs of wheel running tests. In particular, special attention was devoted to the development of horizontal cracks inside the concrete. Furthermore, static analysis was performed to highlight the difference in the failure process given by the fixed point load and the one caused by the moving load. Considering a particular failure mechanism of the deck under moving load, setting a proper limit states and control level for engineering practice was strongly required.
\end{abstract}

Key Words : composite slab, studs, ribs, interface element, horizontal crack, FEM

\section{INTRODUCTION}

The use of steel-concrete composite bridge slabs (hereafter composite slabs) has been increasing. The running wheel tests developed for reinforced concrete (RC) slabs ${ }^{1)}$ showed that composite slabs have the ability to withstand a prescribed magnitude of load imposed with the given number of repetitions $^{2), 3), 4)}$. Accordingly, this revealed that the fatigue resistance of a composite slab was greater than or equal to that of a PC slab. However, the failure mechanism of composite structures are also known to depend on various specifications of shear connector elements, such as studs and ribs ${ }^{5), 6)}$. Moreover, it is not easy to determine standard design and verification equations taking into consideration concrete fatigue damage.

One of the authors has thus far conducted a numerical analysis-based study using nonlinear finite element analysis (code: COM3D) based on the elasto-plasticity/failure constitutive laws of concrete together with a smeared crack model, in order to clarify the failure mechanisms of composite slabs that have relatively 'rigid' shear connectors ${ }^{7), 8), 9)}$. These studies accurately reproduced the shapes of steel members using the solid elements and the initial bond and friction at the interface element between the bottom steel plate/shaped steel and the concrete material. The studies successfully showed not only the entire load-displacement properties, but also the occurrence and development originating from the tip of steel elements inside the concrete. For the next step, this study investigates a Robinson-type composite slab that has relatively 'soft' shear connector, headed studs.

An extremely large number of studs acting as shear connectors installed in a slab makes it unrealistic to reproduce the forms of the individual stubs using the solid elements to conduct finite element analysis of the slabs. For this reason, it is necessary to make a model of the effect of the studs using a specific method.

However, since the relationship between the shear force and displacement obtained by tests are easily influenced by the constraints during testing ${ }^{10)}$, and since the testing was performed under the uniaxial 
condition, it is difficult to directly apply this into three-dimensional analysis. Therefore, this study adopted a macro-model ${ }^{11)}$ described as a method for setting the elasticity as interface element characteristics between the bottom steel plate and concrete elements in the vertical and shear directions for the unit surface area of each bottom steel plate, including studs. One of the authors tried to analyze slab fatigue behavior and the main structure ${ }^{12)}$.

This study first conducted sensitivity analyses to reproduce previous running wheel tests ${ }^{3)}$, then determined the initial bond values of the steel-concrete interface element. Next, the strains of concrete and steel materials obtained from the verified model were picked up for the analysis of the failure process. The authors focused on a key step in the failure process, particularly to clarify how horizontal cracks inside the concrete were formed and progressed. Finally, static analysis was carried out to compare cracking process of concrete inside composite slab with that acquired from the analysis in the running wheel tests. It is hoped that this study will contribute to the planning and maintenance of composite bridge slabs after implementation.

\section{NUMERICAL ANALYSIS MODEL}

\section{(1) Overview of reproductive model}

Figure 1 provides an overview of the test bridge slab used in past running wheel tests ${ }^{3}$. The test bridge slab is $2800 \mathrm{~mm}$ wide, $4500 \mathrm{~mm}$ long, and has a slab span of $2500 \mathrm{~mm}$ that is $209 \mathrm{~mm}$ thick. The studs have a size of $\varphi 16 \mathrm{mmx} 120 \mathrm{~mm}$ and the side ribs are made of $100 \mathrm{mmx} 16 \mathrm{~mm}$ of flat steel. The standard spacing between studs is $250 \mathrm{~mm}, 750 \mathrm{~mm}$ for transverse ribs, though their spacing near the joint of bottom plate are slightly varied. The distance from the top surface to the center of the reinforcing bar in the span direction is $40 \mathrm{~mm}$, and D16 has been installed with $250 \mathrm{~mm}$ spacing. In the longitudinal direction, the bottom steel plate has a $300 \mathrm{~mm}$ wide bearing plate on round steel bars, whereby the long side provides simple support, while the short side provides elastic support using $\mathrm{H}-300 \times 300 \times 15 \times 10$ shaped steel beams.

The wheel load, as shown in the specifications for highway bridges, has a $500 \mathrm{~mm} \times 200 \mathrm{~mm}$ contact area that moves back and forth at a range of $3000 \mathrm{~mm}$ in the longitudinal direction.

\section{(2) Conditions of numerical analysis}

a) Finite element model

Figure 2 gives an overview of the analysis model.

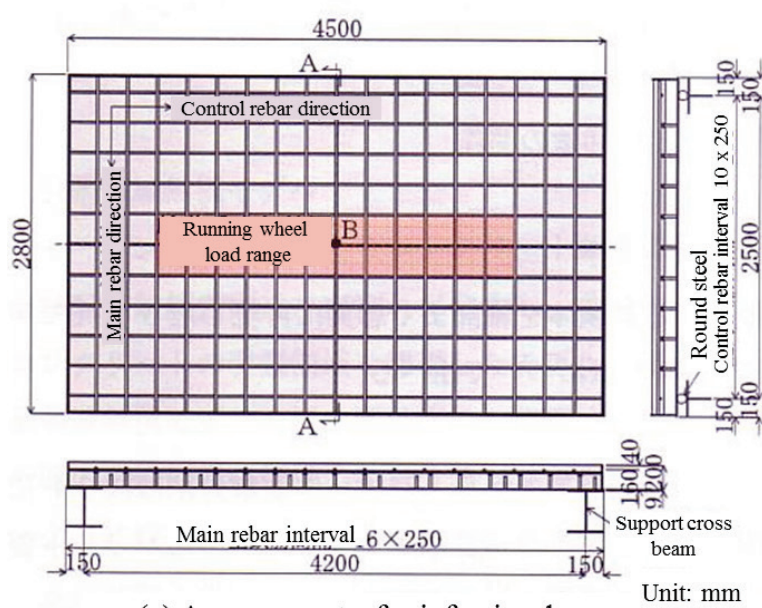

(a) Arrangement of reinforcing bars

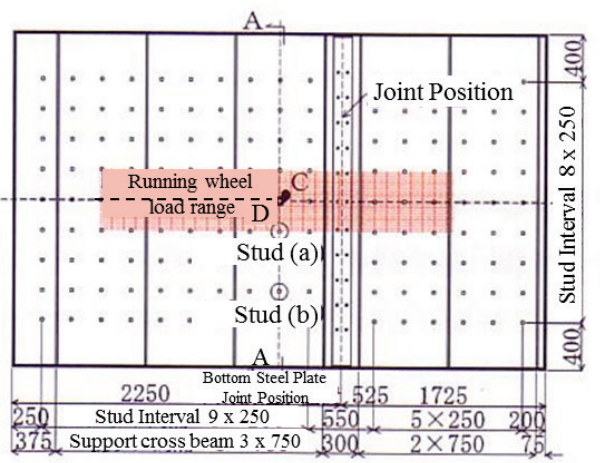

(b) Bottom Steel Plate Unit: $\mathrm{mm}$

Fig. 1 Overview of the test composite bridge slab ${ }^{3)}$.
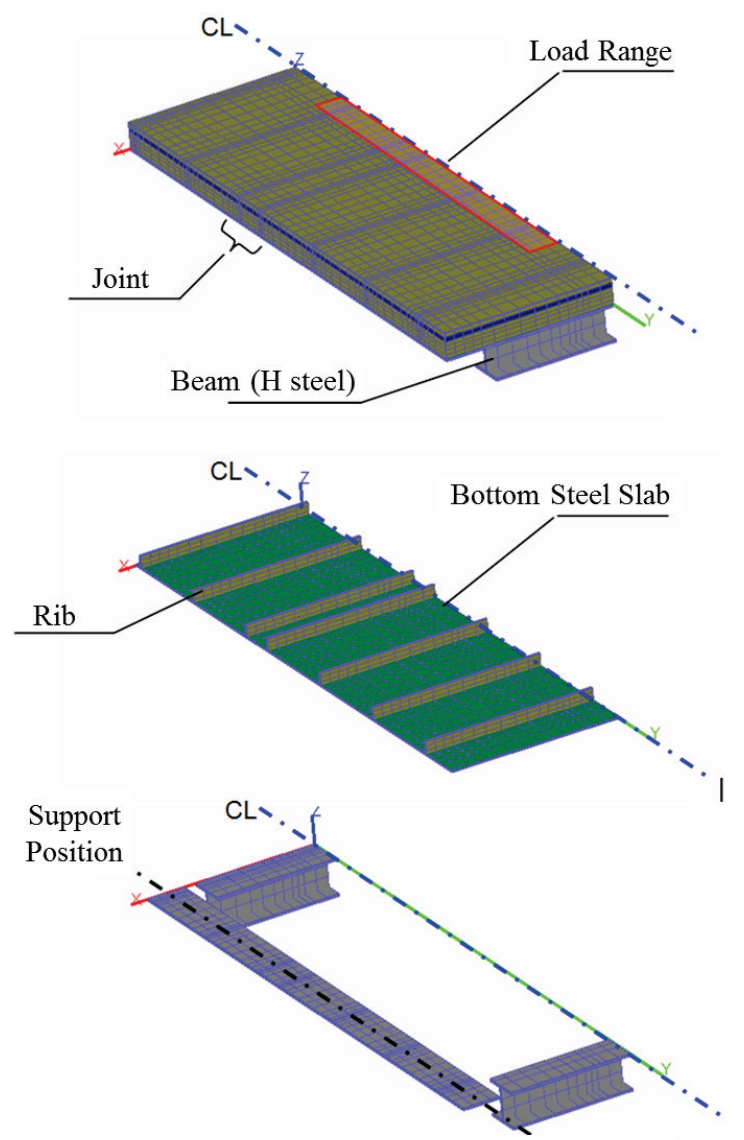

Fig. 2 Analysis model. 
In the light of symmetry of a slab, only half of the slab was modeled from the centerline to the edge. The ribs welded onto the bottom steel plate were reproduced using solid elements, while for the studs, elasticity was set at the interface element between the bottom steel plate and the concrete material based on stud rigidity. The stud forms themselves were not modeled.

The finite element used an 8-node isoparametric element, while the compressive strength of concrete used the results of materials testing, as shown in Table 1. The rebars of D16 arranged in longitudinal and transverse directions were modeled as 40mm-thick RC element layer. Other parts were set as plain concrete elements. Tension softening characteristics were set in accordance with past study ${ }^{13)}$.

For the support condition, a 300mm-wide supporting steel plate under the bottom slab was added into the model and its centerline was assumed to be the vertical support. The H-300x300x15x10 cross beams were also brought into the analysis model. The model incorporated 12,700 nodes, and 10,408 elements (composed of 8246 solid, and 2,162 interface elements).

\section{b) Steel-concrete interface layer}

Two types of joint elements were installed at the steel-concrete interface element. In both the opening and shear directions, the joint elements between the bottom steel plate and concrete considered only the elasticity of the studs, which were thought to dominate the behavior. Neither the initial adherence nor friction was taken into consideration. This was because there was no failure in the studs after completion of the test in the referring experiment, and this was deemed unnecessary in considering nonlinear characteristics due to the plasticized or failed studs. The elasticity was set as shown in reference ${ }^{14)}$.

The joint element between the rib side and the concrete material shows linearity ${ }^{8)}$ until it exceeds the initial bond strength, at which point it follows general friction laws with the coefficient of friction of $0.6^{15)}$. No consideration has been taken about any decrease in the coefficient of friction due to fatigue.

\section{c) Concrete and RC element constitutive laws}

High-cycle fatigue damage (reduction in elasticity and development of plastic deformation) of both concrete and reinforced concrete has been considered in the relationship between stress-strain related to compression, tension, or shear transferring across crack. ${ }^{16)}$ The past study had reported that high-cycle fatigue failure of RC slab can be reproduced using these constitutive laws ${ }^{17)}$.
Table 1 Material properties for analysis.

\begin{tabular}{c|c|c|c}
\hline \multirow{2}{*}{ Item } & $\begin{array}{c}\text { Strength } \\
\text { Characteristics } \\
\mathrm{N} / \mathrm{mm}^{2}\end{array}$ & $\begin{array}{c}\text { Elastic Cocfficient } \\
\mathrm{N} / \mathrm{mm}^{2}\end{array}$ & Poisson Ratio \\
\hline \multirow{2}{*}{ Concrete } & $\begin{array}{c}\text { Compression Strength } \\
\mathrm{f}_{\mathrm{c}}=37.6\end{array}$ & \multirow{2}{*}{$2.94 \times 10^{4}$} & 0.20 \\
\cline { 2 - 3 } & $\begin{array}{c}\text { Tensile Strength } \\
\mathrm{ft}_{\mathrm{t}}=2.58\end{array}$ & \\
\hline Rebar (D16) & Yield Point $\mathrm{f}_{\mathrm{y}}=352.6$ & $2.0 \times 10^{5}$ & 0.30 \\
\hline $\begin{array}{c}\text { Bottom Steel } \\
\text { Plate }\end{array}$ & Yield Point $\mathrm{f}_{\mathrm{y}}=281.6$ & $2.0 \times 10^{5}$ & 0.30 \\
\hline Rib & Yield Point $\mathrm{f}_{\mathrm{y}}=281.6$ & $2.0 \times 10^{5}$ & 0.30 \\
\hline
\end{tabular}

Table 2 Analyzed case with initial bond force as a parameter.

\begin{tabular}{c|c|c|c}
\hline \multirow{2}{*}{ Analyzed Case } & \multicolumn{2}{|c|}{ Initial Adhesion Force $\mathrm{N} / \mathrm{mm}^{2}$} & \multirow{2}{*}{$\begin{array}{c}\text { Coefficient of friction after } \\
\text { adhesion breakage }\end{array}$} \\
\cline { 2 - 3 } & Opening direction & Shear direction & 0.6 \\
\hline Case 0 & 0 & 0 & 0.6 \\
\hline Case 1 & 1.0 & 25.0 & 0.6 \\
\hline Case 2 & 3.05 & 25.0 & 0.6 \\
\hline Case 3 & 5.0 & 25.0 & \\
\hline
\end{tabular}

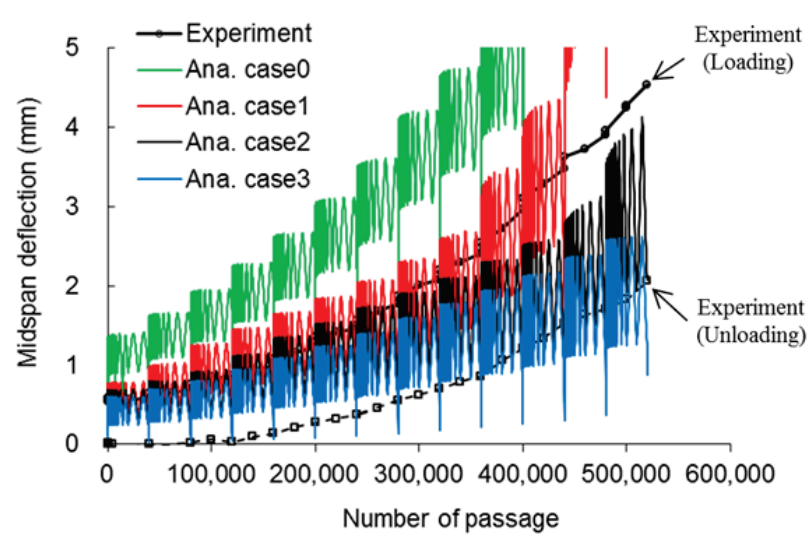

(a) Relationship between midspan deflection and number of load passages

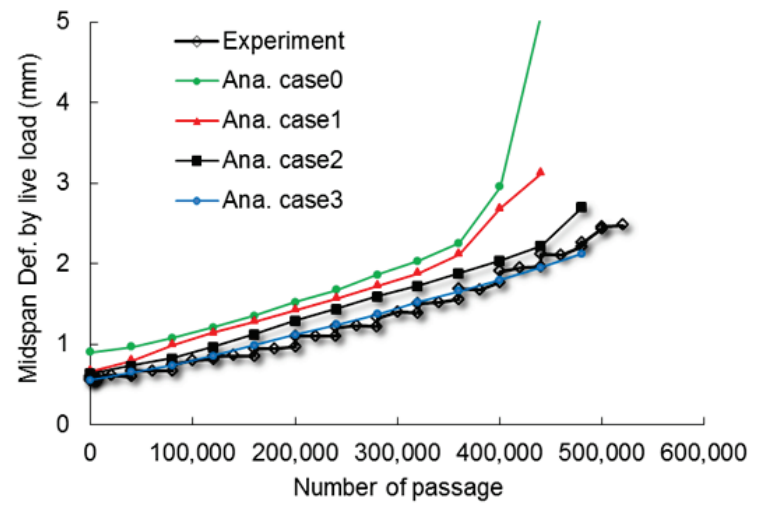

(b) Relationship between the largest live load deflection and number of load passages

Fig. 3 Progress of midspan deflection. 


\section{(3) Identification of initial bond}

In order to investigate the influence of initial bond in response to repetitions of a running load, a parametric study was carried out whereby the initial bond was used as a parameter. The values were from referencing studies ${ }^{18), 19), 20)}$, and were examined in the current study. These settings can be seen in Table 2 .

The running load applied on the area of $200 \mathrm{~mm} \mathrm{x}$ $500 \mathrm{~mm}$ moved longitudinally and increased its intensity gradually from $157 \mathrm{kN}$ to $392 \mathrm{kN}$, in increments of $19.8 \mathrm{kN}$ for every 40,000 passages.

The number of load passages and the dynamic deflection process of midspan are shown together with the experimental result in Fig. 3(a), while Fig. 3(b) shows the picked up midspan deflection due to a live load. The live load deflection was obtained by subtracting the deflection with no load (residual deflection) from the maximum deflection produced when the load passed the center of the slab.

The computed deflection of case 0 , which does not consider initial bond, was excessively large from the initial stage when compared to the other three cases (Fig. 3(a)). The slip between the steel and concrete occurred when $157 \mathrm{kN}$ load was put at the edge of the slab. Further, the slip became large when the load came onto the midspan of slab. This resulted in the loss of composite action of slab and the excessive large deflection of case 0 . On the other hand, in case 3 with a large initial bond, the computed deflection was well matched with the experimental value at the beginning of loading. However, the progress of deflection was small, and after 52,000 repetitions, the deflection was roughly half that of the experimental one. In terms of the progress of maximum deflection, case 2 exhibited a tendency to be closest to the experimental values from beginning to end.

Next, the deflections due to live loads were compared (Fig. 3(b)). Case 0 showed approximately 1.5 times larger deflections than those of the experimental values. This means that the non-consideration of initial bond strength caused the large plastic deformation (residual deflection). Among cases 1 to 3, the case considering higher initial bond showed better consistency with the experiment.

This parametric study showed that the total behavior of the slab could be reproduced even by the method proposed in this study to model studs. Moreover, it can be said that case 2 well reproduced the experiment tendency. Hereafter, the authors adopted case 2 to conduct an analysis of the fatigue failure process for the composite slab in this study.

\section{INVESTIGATION OF THE FAILURE MECHANISM UNDER RUNNING WHEEL LOAD}

\section{(1) Progress of strain}

\section{a) Bottom steel plate}

Figure 4 shows a comparison of the experimental and analytical processes of elastic strain at the center of the bottom steel plate obtained from the previous analysis case 2 . The analyzed strain is the average strain of the referential element of the bottom steel plate. A qualitative consistency was observed as the increase of strain associated with increase of load. A quantitative consistency was also confirmed by the maximum strain staying under $150 \mu$ in both directions. In other words, both the experiment and analysis recorded strains in the elastic range around $30 \mathrm{~N} / \mathrm{mm}^{2}$.

Figure 5 compares the maximum deflections in the traveling direction of the load and in the transverse direction. The analysis showed strains in both directions that were almost consistent from beginning to end. The slab in the analysis was thought to behave as two-way slab. On the other hand, in the experiment, longitudinal strain was obviously larger from the initial loading through to completion. This difference might come from the difficulty of reproducing the boundary conditions of the experiment.

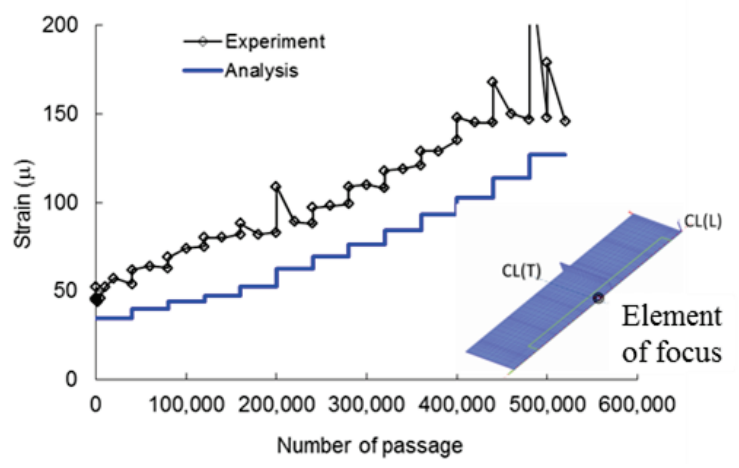

(a) Strain in the direction of load traveling

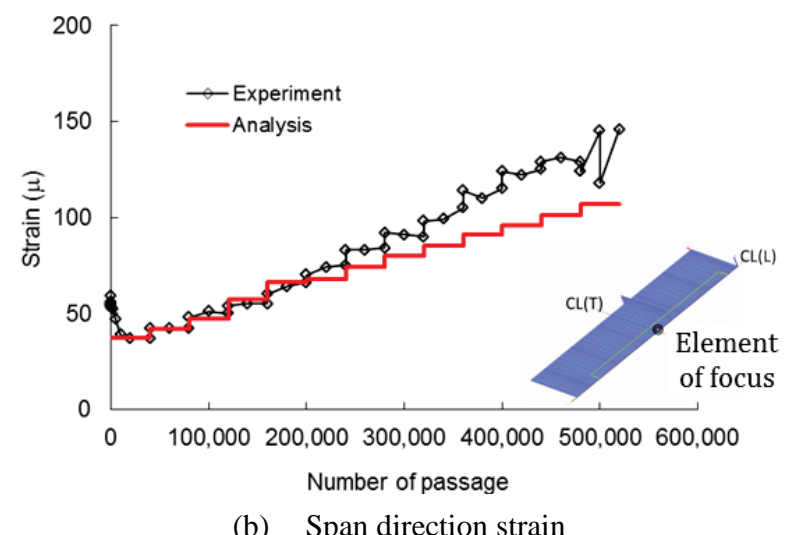

(b) Span direction strain

Fig. 4 Progress of strains at bottom steel plate. 


\section{b) Concrete}

Figure 6 shows the covering concrete at the center of the slab (element number 7201) and the concrete material (element number 4993) located at the upper end of the ribs, where horizontal cracks may be generated. The strains extracted from the referential elements versus the number of load passage are summarized in Fig. 7.

The compressive strains of covering concrete (element number 7201) increased in both directions with the increase in the number of load passages (Fig. 7(a)). This is reasonable when the slab behaves as a two-way slab. However, from 480,000 to 520,000 passages of load, there was a rapid change in strains, and even the longitudinal strain turned to tension. The occurrence of cracks along the transverse direction is inferred.

However, tensile strain in the concrete between the ribs (element number 4993) showed a striking increase in transverse direction with above 120,000 load passages (load of 198kN, Fig. 7(b)). This was a contradiction. The strains of the element was expected to stay in compression, because the element was located above the estimated neutral axis. The contradiction indicated that the strain distribution was different from that expected by design.

\section{(2) Movement of neutral axis}

The horizontal strains of referential elements at $40,000,160,000,480,000$, and 520,000 passages were plotted on a vertical coordinate set along the depth of the slab (Fig. 8). The strain in the direction of load traveling was almost linear in form until 160,000 , and the neutral axis was seen at a depth of $130 \mathrm{~mm}$ (70mm from the top surface of the bottom steel plate). However, the strains in the span direction were not linearly distributed, whereby the excessive compression strain occurred in the covering concrete layer (Fig. 8(b)). Considering this, in combination with the rapid increase in tension strain found from 120,000 for element number 4993, the cracks starting at the tip of the ribs reached the center of the span. This suggested that the layered concrete slab did not show composite action any more.

Under conditions where positive bending occurs as shown in this study, it is well known that the composite effect of steel and concrete using studs is sufficiently high when the studs are designed by following general design guidelines of composite structure shear connectors ${ }^{22)}{ }^{23}$. A high degree of composition is also achieved by means of the elastic stiffness of the studs between the bottom steel plate and the concrete slab in this study. In contrast, slips

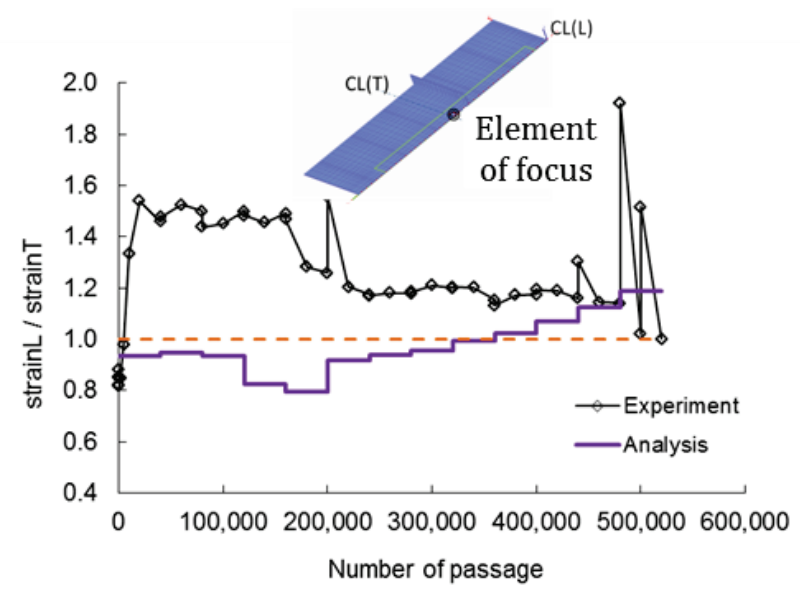

Fig. 5 Ratio of strain of bottom steel plate longitudinal / transverse directions.

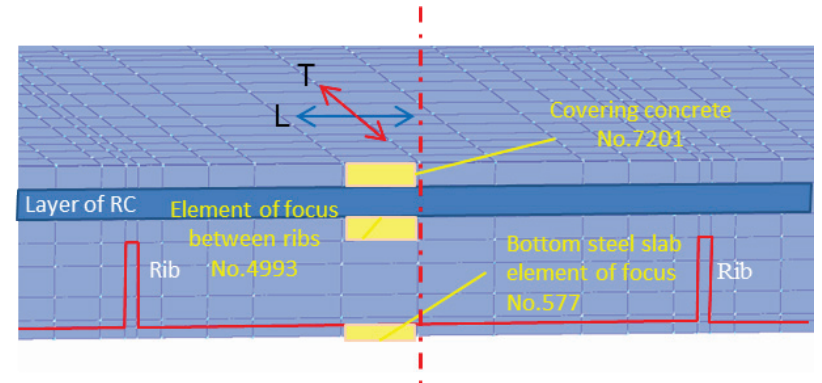

Fig. 6 Location of referential elements.

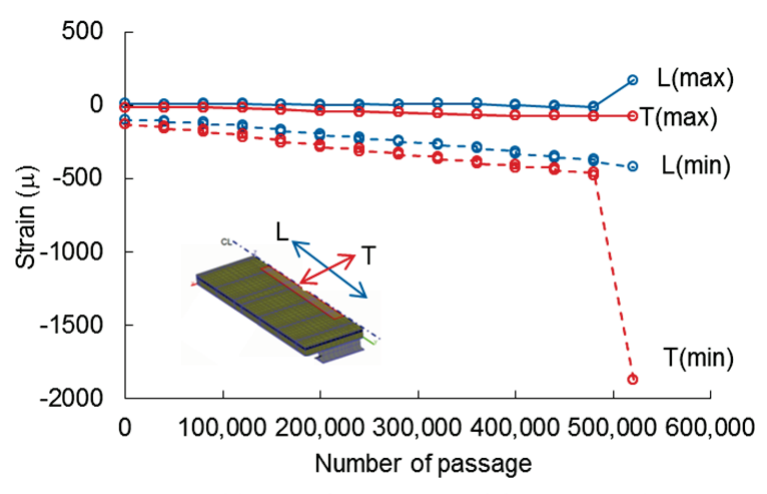

(a) Covering concrete (element 7201)

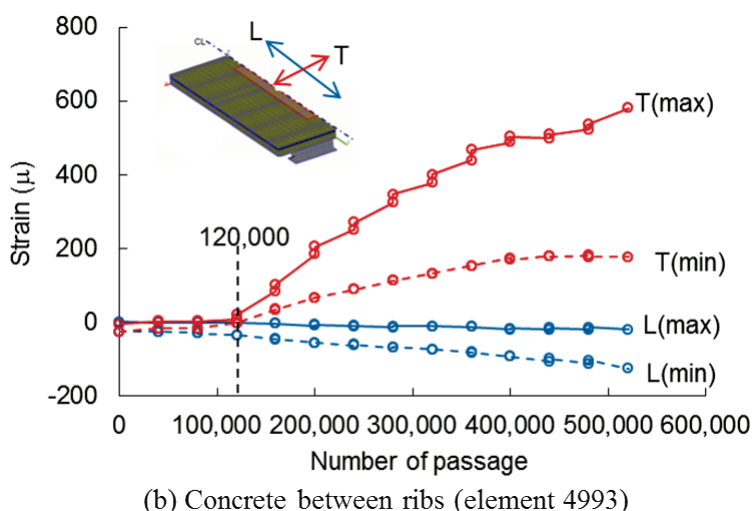

Fig. 7 Progress of strains of referential elements (two-way). 
and openings could easily occur between rib and concrete, because the behavior between the rib and the concrete is governed by the elasto-plastic mechanism arising only from bond and friction.

\section{(3) The initiation of horizontal cracks and the failure process}

a) Analysis based on the progress of concrete element strain

The strains at the midspan of slab shown in the previous section convinced us that the initiation and progress of horizontal cracks were successfully reproduced by FE analysis in this study. As shown in Fig. 9, strains of the concrete elements were derived at several locations in order to identify where these cracks originated and spread to. The elements, from which strains were derived, from midspan to the edge, L1 through L6, were along the running load direction, while T1 through T4 were the elements that followed the cross-section from midspan to the main beam.

The maximum strains recorded for the load running were picked up for the concrete elements at the rib height. Note that the maximum strains of each elements were not recorded at the same time. Figure 10 shows a comparison of strains between L1 to L6 along the load traveling direction. Although the value of strain in the longitudinal direction is generally small, the strains of L4 located at the side of rib show tension. Strains of L2 turn to tension from

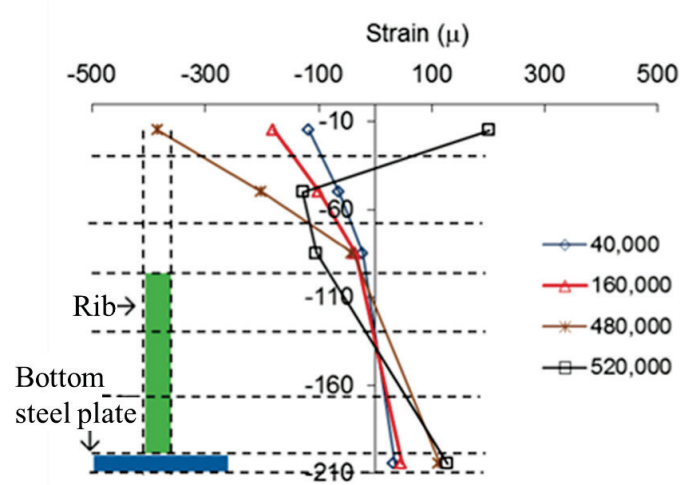

(a) Running load direction (bridge axis direction)

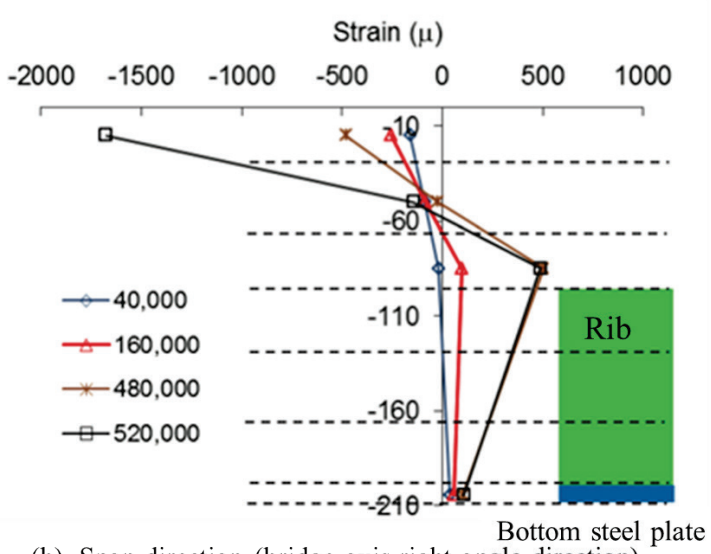

(b) Span direction (bridge axis right angle direction)

Fig. 8 Distribution of strain along depth of deck.
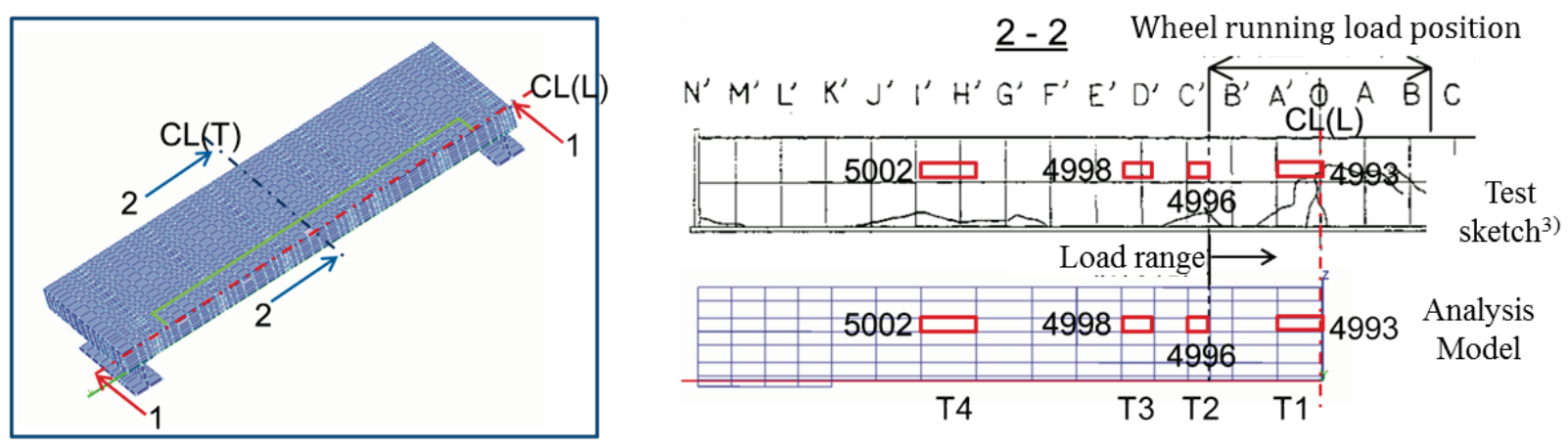

$$
\underline{1-1}
$$

$22^{\prime} 21^{\prime} 20^{\prime} 19^{\prime} 18^{\prime} 17^{\prime} 16^{\prime} 15^{\prime} 14^{\prime} 13^{\prime} 12^{\prime} 11^{\prime} 10^{\prime} 9^{\prime} 8^{\prime} 7^{\prime} 6^{\prime} 5^{\prime} 4^{\prime} 3^{\prime} 2^{\prime} 1^{\prime} \phi^{\prime} 1 \quad 2 \quad 3 \quad 4 \quad 5 \quad 6 \quad 7$

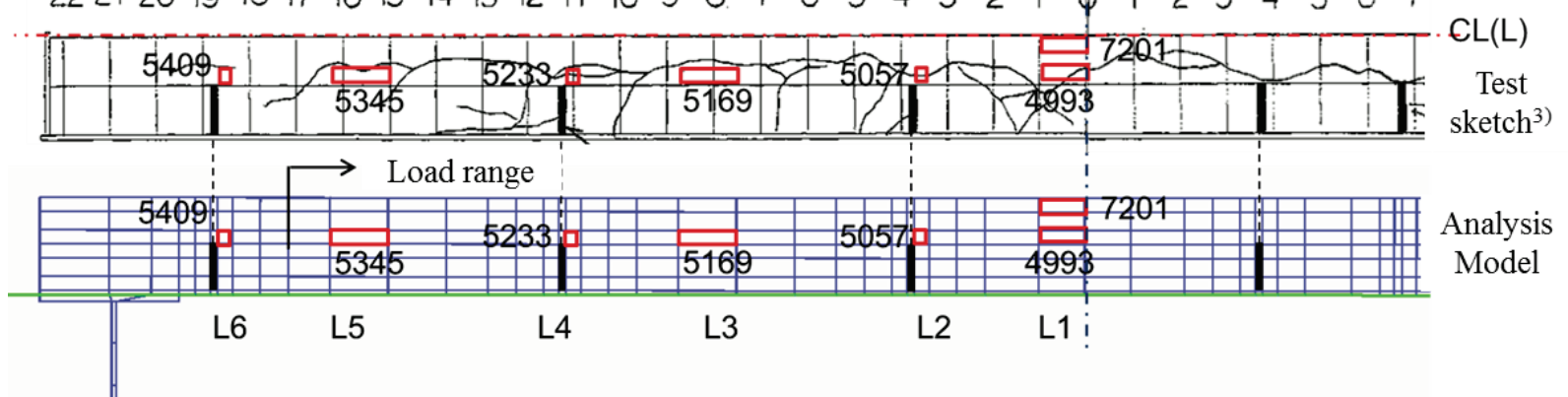

Fig. 9 Location of concrete elements where strain was derived. 


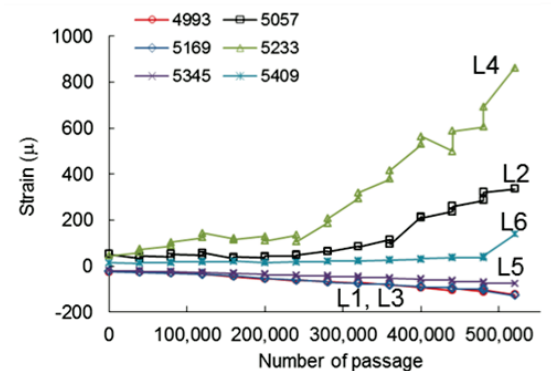

(a) Strain in the running load direction

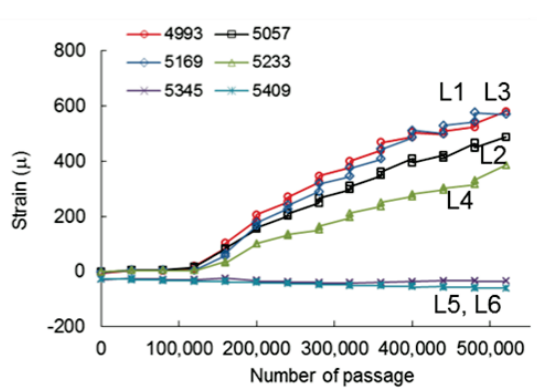

(b) Span direction strain

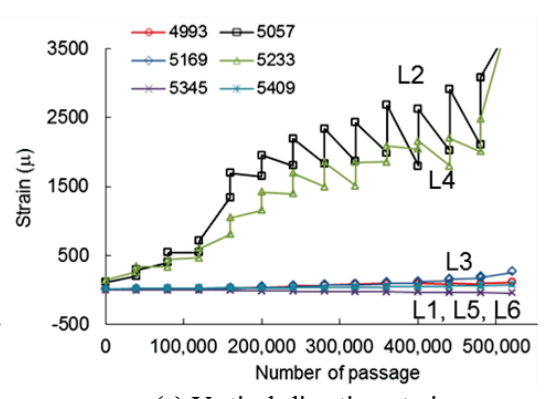

(c) Vertical direction strain

Fig. 10 Comparison of transition of concrete strain at cross-section in running load direction (Fig. 9, cross-section 1-1).

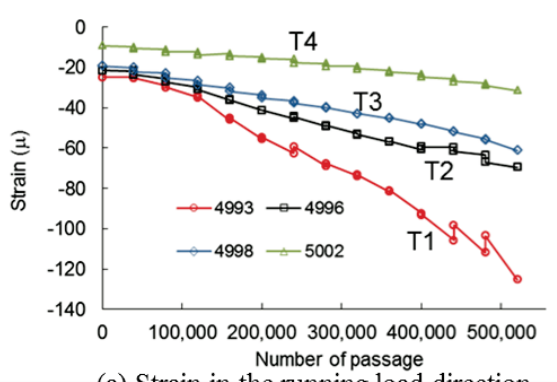

(a) Strain in the running load direction

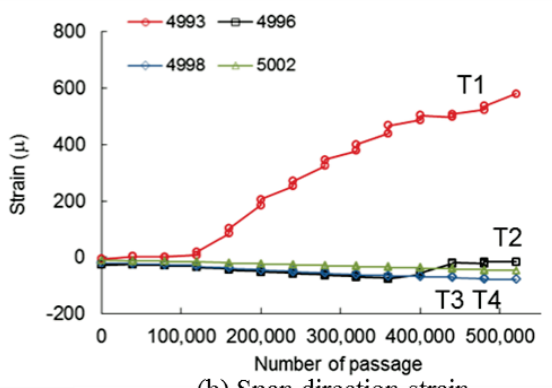

(b) Span direction strain

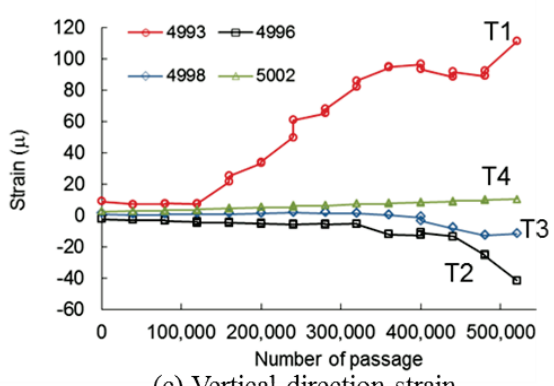

(c) Vertical direction strain

Fig. 11 Comparison of transition of concrete strain at span direction cross-section (Fig. 9, 2-2 cross section).

about 400,000 repetitions of load passages (Fig. 10(a)). On the other hand, strains in the span direction of L1, L2, L3, and L4 become tension from 120,000 repetitions onward (load of $198 \mathrm{kN}$ ). This indicates the development of horizontal cracks due to bending action in the span direction (Fig. 10(b)).

In addition, there was notable vertical strain at the side of the ribs for L2 and L4 (Fig. 10(c)). Taking this into consideration by reference to Fig. 8(b), there was evidently an area where the strains were no longer linearly distributed from 120,000 repetitions of load passages (load of $198 \mathrm{kN}$ ). In other words, the cracks from the tip of the ribs gradually connected with other cracks in the area.

Comparing T1 through $\mathrm{T} 4$ revealed that strain in the direction of the moving load generally increased with the number of load repetitions (Fig. 11(a)). The strains in the span direction showed compression except that of T1. The strain of T1 in the span direction showed tension from 120,000 passages of load (load 198kN) onwards (Fig. 11(b)). Here, attention should be focused on the location of elements. T1 was directly below the lane, while T2 to $\mathrm{T} 4$ were away from the lane with the load. This means that bi-stratification due to horizontal cracks emerged only below the lane with the load, while spreading in the span direction was relatively small. This was consistent with the experimental results.

Vertical strain changes with relatively small values of roughly $\pm 20 \mu$ for cases other than T1, and they

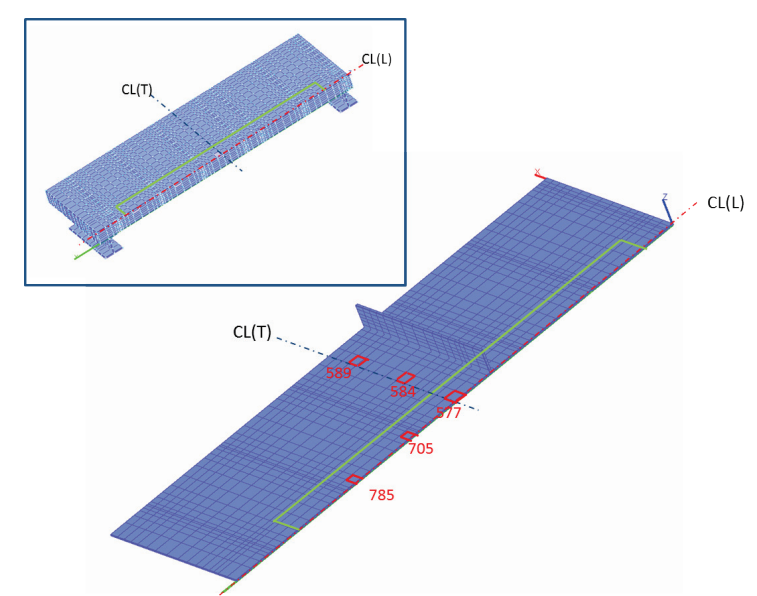

Fig. 12 Location of referential element of bottom steel plate.

do not directly show the opening of cracks (Fig. 11(c)).

\section{b) Relationship between the strains of the bottom steel plate and horizontal cracking}

In order to investigate the influence of the initiation and progress of horizontal cracks on other parts, strains of bottom steel plate elements, other than element number 577, were derived: element 705 , which was $500 \mathrm{~mm}$ away from the center in the running load direction directly below the load range; 785 , which was $1000 \mathrm{~mm}$ away from the center; 584 , which was $500 \mathrm{~m}$ away from the middle of the plate load area on the support side; and 589, which was 
850mm away from the middle (Fig. 12).

At first, the elements directly below the running load $(577,705,785)$ were compared. Strains in the running load direction proceeded with relatively small values for element numbers 705 and 785 in the area isolated from the center of the deck by the ribs (Fig. 13(a)). This indicated that the stresses were not efficiently distributed to all area of slab due to the initiation and progress of horizontal cracks in the vicinity of the center of the deck. On the other hand, strain in the span direction tended to increase with an increase in running load repetitions (Fig. 13(b)).

In the next section, the strains of element numbers 577, 584, and 589 will be compared. Longitudinal strains of these elements generally increased with increase in number of load passage. The values depended on the distance from the running load (Fig. 14 (a)). Transverse strains of these elements also showed a similar trend from the outset. Careful observation showed that the rate of increase in strains of element number 584 grew after 120,000 load repetitions. Then, the strain of element 584 reached the center of the deck directly below the load at 480,000 repetitions (Fig. 14 (b)). While this is not a rapid change, it is possible that the increase in strain is related to the increase in the area of slip or opening between the ribs and concrete.

The above change in strain of the bottom steel plate is behavior in the elastic region. Although it helps in guessing the initiation and progress of horizontal cracks in the concrete slab during running wheel tests, it is difficult to use for definitive judgment.

\section{c) Estimating failure process related to develop- ment of horizontal crack}

In accordance with the analyses of strains of referential elements, information in terms of initiation and progress of horizontal cracks are summarized herein.

First, cracks appeared from the tip of the ribs below the running load at roughly 120,000 repetitions (load of 198kN) and these cracks opened further in the vertical direction with further repetitions of load. At the same time, just below the wheel load, there emerged a difference in horizontal strain between the upper layer and bottom layer for the bending in the span direction. The upper layer is concrete above the horizontal cracks, and the bottom layer is the part that consists of ribs, concrete in-between ribs and bottom plate. In-plain theory is no longer partially achieved here.

Continuing further repetition of load, horizontal cracks were interactively connected in the running load direction. After the load reached 480,000

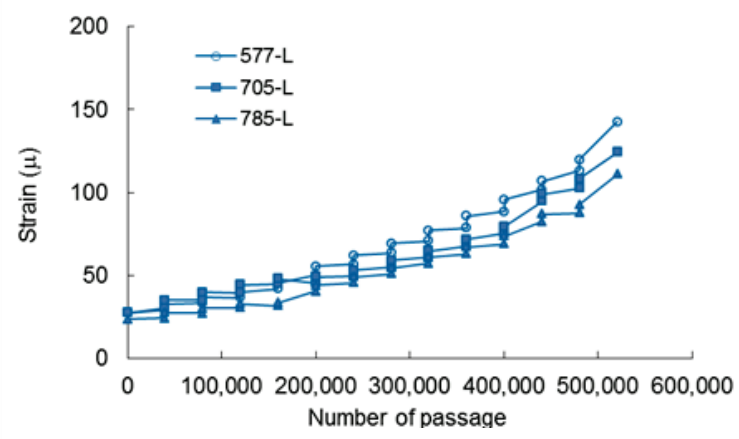

(a) Strain in the running load direction

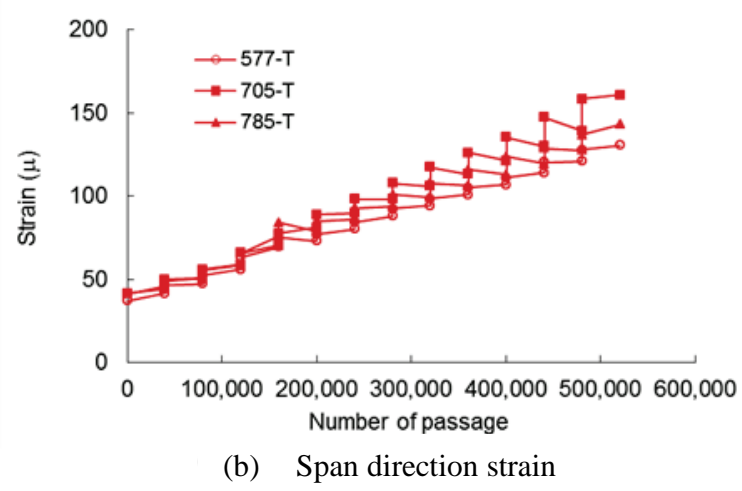

Fig. 13 Comparison of bottom steel plate strain at cross-section in the running load direction.

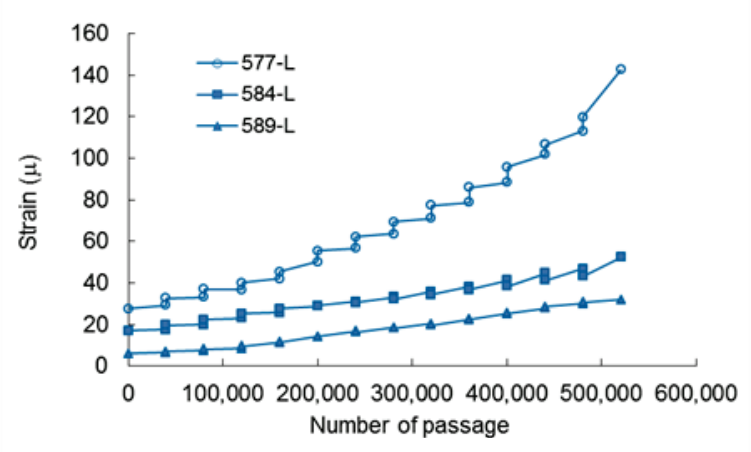

(a) Running load direction strain

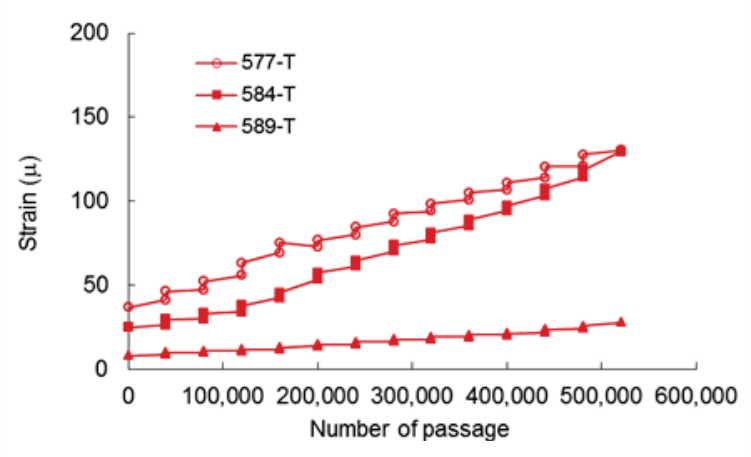

(b) Span direction strain

Fig. 14 Comparison of bottom steel plate strain at span direction cross-section 
repetitions and $392 \mathrm{kN}$, longitudinal cracks, as well as compression failure of concrete, could be observed in the upper layer of concrete.

The horizontal cracks were confirmed below the moving load and their spread was small in the transverse direction. In other words, it was not easy to presume the initiation and progress of horizontal cracks from the strain of the bottom steel plate.

\section{EVALUATION OF FATIGUE RE- SISTANCE BASED ON THE FAILURE MECHANISM}

\section{(1) Comparison of the failure mode in static analysis}

In order to investigate the relationship between the process of failure based on static tests, which could be easily performed in practice, and the failure process studied by running wheel tests, the authors performed static analysis by using the exact same model in the previous section. The loading area at midspan was $500 \mathrm{~mm}$ (transverse) by $200 \mathrm{~mm}$ (longitudinal). Displacement control at a rate of $0.1 \mathrm{~mm} / \mathrm{sec}$ was applied. Fig. 15 shows the relationship between the load and the midspan deflection. The maximum bearing force was $1640 \mathrm{kN}$. Yielding occurred at this maximum bearing force after minor changes in stiffness were observed at around $500 \mathrm{kN}$ and $1500 \mathrm{kN}$. Here, it was apparent that even the maximum of $395 \mathrm{kN}$ was equivalent to roughly $25 \%$ of the maximum load-bearing ability. The load used in the running wheel tests was $158 \mathrm{kN}-395 \mathrm{kN}$.

The strains of the following elements, which were the targets in the analysis of the running wheel tests: 4993 (L1) in the vicinity of midspan, 5057(L2) at the rib edge, 5169(L3) to the adjacent rib, and 5233(L4) at the edge of the adjacent rib, were picked up again. Fig. 16 shows the progress of strain leading to $10 \mathrm{~mm}$ deflection. For element 5057(L2), strain shifted to tension at a deflection of $4.0 \mathrm{~mm}$ in the longitudinal direction at the rib edge, even though there was no large variation in others (Fig. 16(a)). Strain of element 5233(L4) no longer corresponded with the strain of 5057(L2) in static analysis. In the transverse direction, strains generally proceeded under compression (Fig. 16(b)), hence they were totally different from the progress of strains observed in the analysis simulating moving load (Fig. 10(b)).

The vertical strain of the rib side element 5057(L2) clearly increased with deflection at 1.6 midspan, even if strain of the adjacent rib edge element 5233(L4) showed almost no change. Suppos-

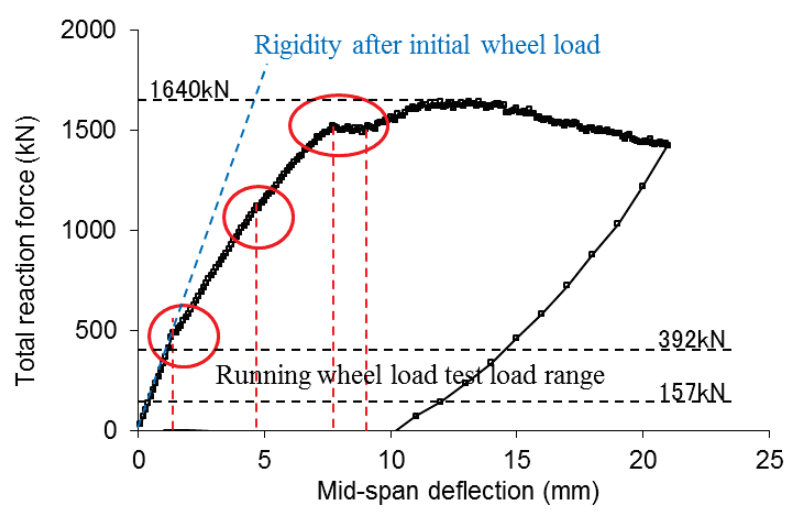

Fig. 15 Relationship between load and midspan deflection.

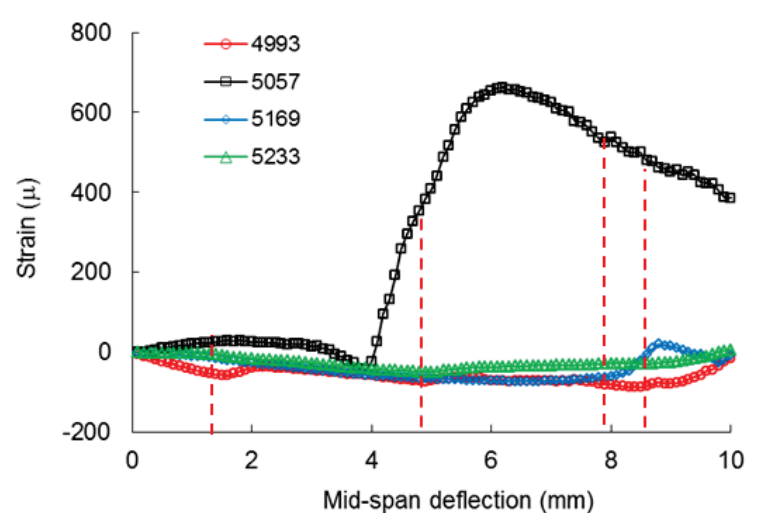

(a) Strain in the moving load direction

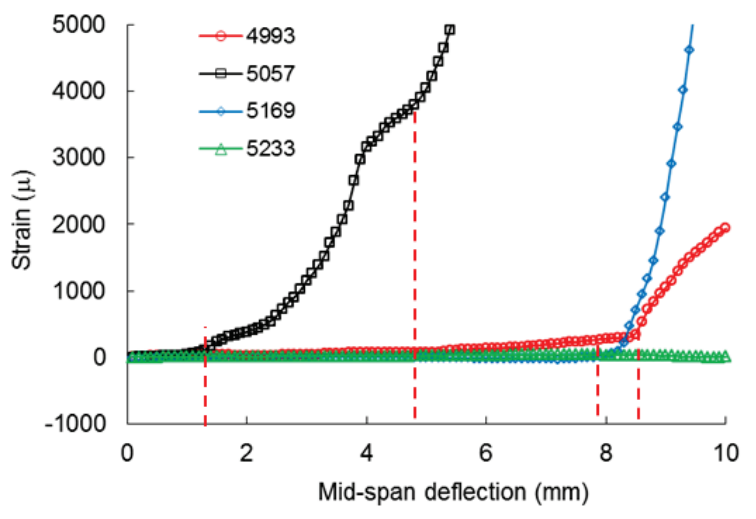

(b) Span direction strain

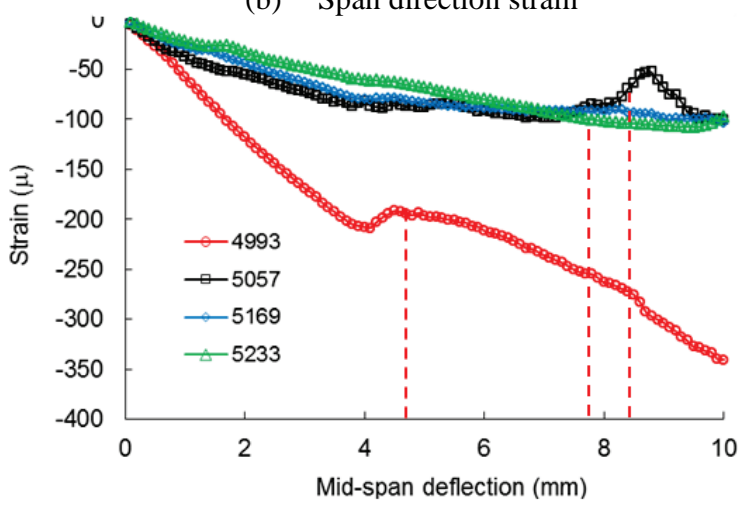

(c) Vertical direction strain

Fig. 16 Cracking process of the target concrete element. 
edly, it is understood that cracks do not occur at the adjacent rib edge in the static load condition. After midspan deflection reached $8 \mathrm{~mm}(1500 \mathrm{kN}$ load), the vertical strain of 5169(L3) and 4993(L1) increased. This indicated an opening of crack in the element 5057(L2) (Fig. 16(c)).

Figure 17 shows the vertical strain distribution for midspan deflections of $1.6 \mathrm{~mm}$ (approx. $500 \mathrm{kN}$ load) and $8 \mathrm{~mm}$ (1500 kN load). At $1.6 \mathrm{~mm}$ (approx. $500 \mathrm{kN}$ load), a concentration of strain can be observed not only below the loading area, but also at the tip of the rib on a cross-section (Fig. 17(a)). At the deflection of $8 \mathrm{~mm}$ (1500 kN load), although there is a notable tendency for strain to develop horizontally towards the middle of the span, it was confirmed that strains did not reach the adjacent rib (Fig. 17(b)). After that, the deflection of slab increased rapidly. That was the ultimate state of this slab.

Note that the static load $500 \mathrm{kN}$ initiating cracks at the rib edge were more than twice the load causing similar cracks in a simulation assuming the wheel

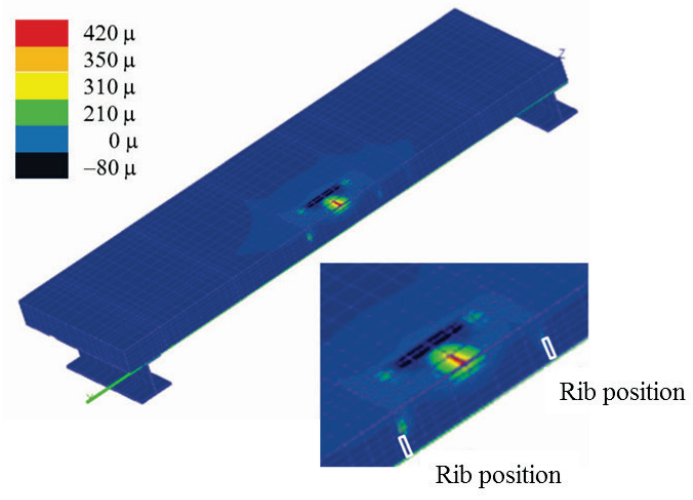

(a) Midspan deflection $1.6 \mathrm{~mm}$ (Approx. $500 \mathrm{kN}$ )

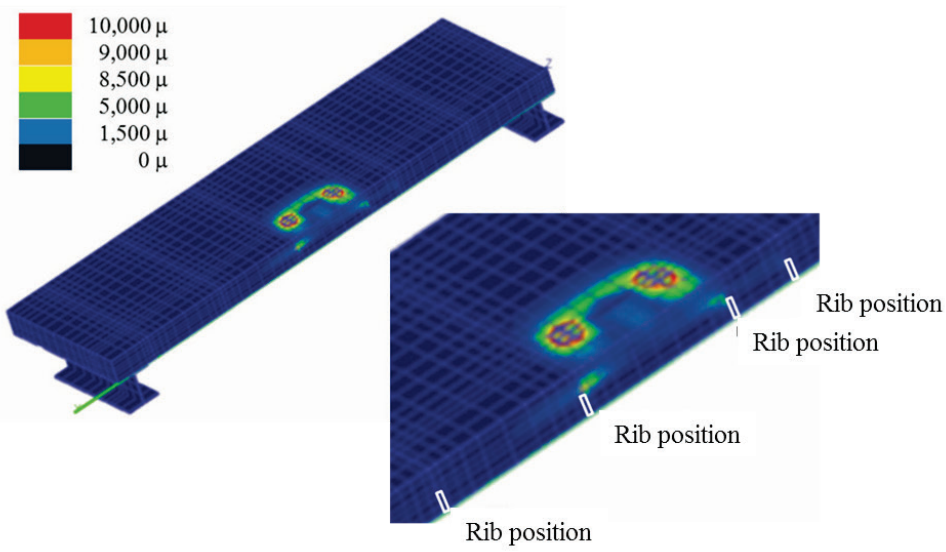

(b) Midspan deflection $8.0 \mathrm{~mm}$ (Approx. $1500 \mathrm{kN}$ )

Fig. 17 Vertical direction strain distribution.

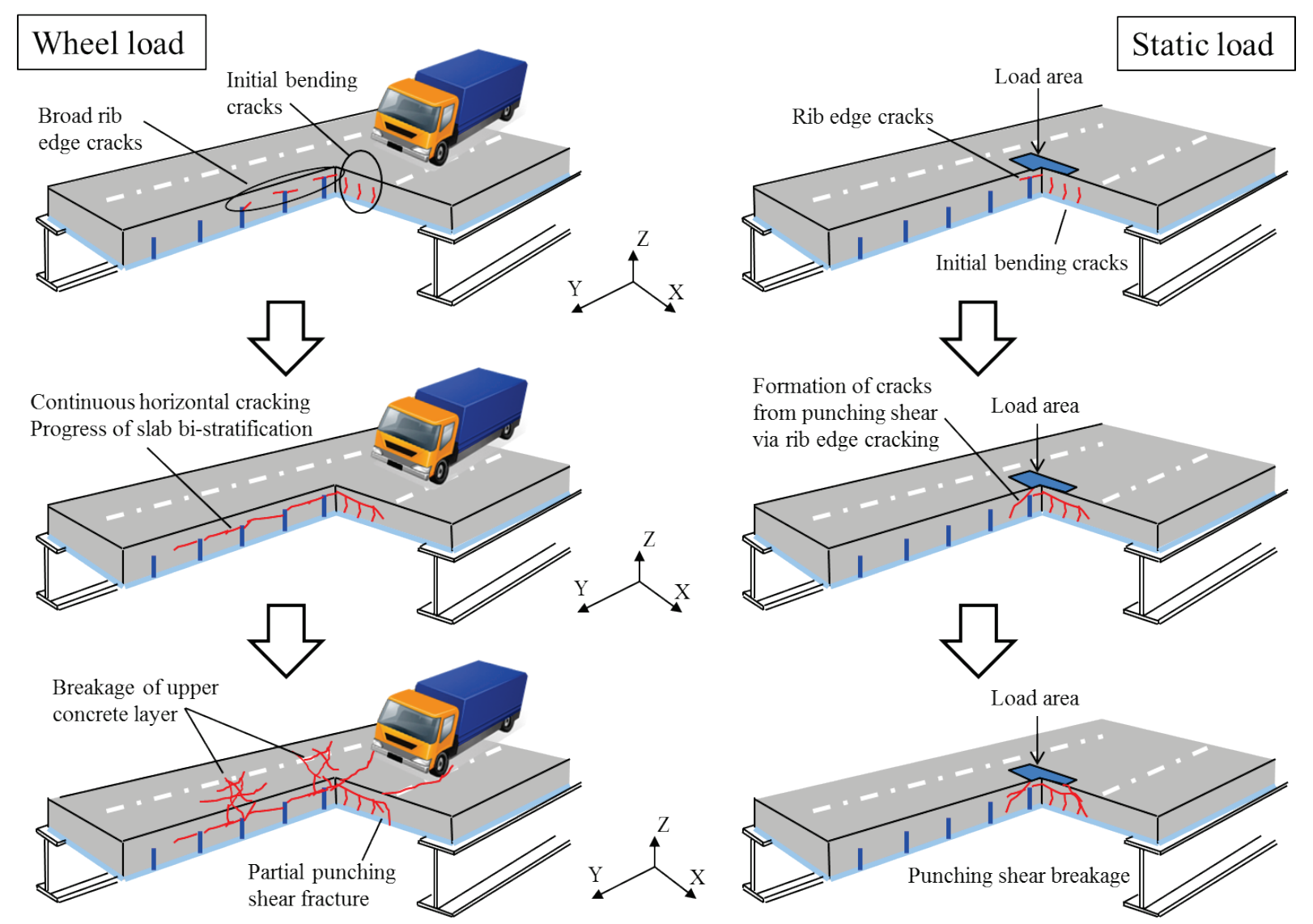

Fig. 18 Fracture process due to the load assumed in this study (Comparison with the process with the static load) 
test. Moreover, in the static analysis, the slab seemed to fail without separation of slab caused by horizontal cracks. The failure process was different from that assumed in the simulation of the running load tests.

\section{(2) Evaluation of fatigue resistance based on the study of failure process}

a) Estimation of the failure mechanism for actual bridge slabs

Figure18 shows the failure process of the composite bridge slab based on the previous numerical analysis for actual bridges. After cracks appeared from the tip of rib due to a moving load, the cracks continuously proceeded horizontally and subsequently separated the slab into two layers. Following the incident, such a condition was created that a thin slab of concrete was laid on the top of a relatively thick composite slab that sustained its composition mechanism with the bottom steel plate. In the thin upper layer, concrete failed because of bending action, and the failure came earlier than the bottom one.

Since the span of the actual bridge was far larger than that of the test slab for the running wheel tests, the authors presumed bending-dominant condition for actual slab as the general case. In the running wheel tests, however, punching shear cracks were observed at the cross-section in transverse direction ${ }^{3)}$ because of the shorter shear span than that of actual bridge. Despite that particular condition in which the shear span of the actual bridge was shorter than that of the specimen in the wheel running test, generating horizontal cracks in terms of composite slab was still possible. Therefore, it is not proper to treat the failure process of composite slab as due to the RC slab.

b) Consideration of evaluation methods for fatigue resistance of composite slab

When fatigue resistance of a composite bridge slab is evaluated for an actual bridge, it is more important to estimate the failure mode than the maximum load- carrying capacity. Thus, the authors value the static test or static analysis ${ }^{9}$ that clarifies the relation between failure mode and its influence factors: spacing of ribs, shape of ribs, and thickness of slab. After the clarification of the failure process, it is necessary to define the limit states for both service condition and ultimate condition in line with the failure mode. The management of actual bridge should stand for the criterion based on the limit states.

In general, even in a case where punching shear is considered to occur easily in static investigations, the composite slab covered by the bottom plate does not lead to spalling of concrete associated with third-party damage. In other words, punching shear failure is not always a critical issue for composite slab. Composite slabs need specific management strategies that differ from those of the RC slab.

Specifically, limit state can be define as compression fatigue failure in the upper concrete layer after the separation of composite slab due to horizontal cracks. As the condition of upper concrete directly affects the running safety of cars, the separation will become, in particular, one of the evaluative indicators for fatigue resistance for actual bridges. With this, if the remaining period (running repetitions) to ultimate limit state could be predicted, time could be effectively used for planning proper maintenance.

\section{CONCLUSIONS}

The failure process of "Robinson-type" steelconcrete composite deck supposing boundary conditions of actual bridge was estimated on the basis of numerical analysis. In particular, the initiation and progress of cracks that originated from the tip of ribs inside the concrete were shown in detail. The following conclusions were obtained from this study:

(1) The effect of shear connector caused by studs of Robinson-type composite deck were converted to the equivalent elasticity of the interface element. The simulated progress of deflection and strains of each component agreed with the experiment.

(2) In a situation of positive bending, the composition between the bottom steel plate and the concrete given by studs was relatively higher than that due to bond and friction between the ribs and the concrete. The slip and opening tended to occur between the ribs and the concrete rather than between the bottom plate and the concrete. The slip and opening caused stress localization that became the starting point of cracks, and the subsequent development of horizontal cracks and separation of slab.

(3) Horizontal cracks were confirmed below the wheel-running, though they had little spread in the transverse direction.

(4) For the static analysis, the model failed with no clear separation due to continuous horizontal crack. This showed that the failure process due to repetitive moving loads differs from the failure process under the static load.

It should be noted that the initial bond and friction coefficients for the interface element between the concrete and steel materials were assumed based on some past experimental studies. These are, in prac- 
tice, sufficiently influenced by strength and the drying and shrinking conditions of concrete. Further investigation is expected.

ACKNOWLEDGMENTS: We wish to express our gratitude to Professor Koichi Maekawa of The University of Tokyo for his valuable comments over the course of this study. Also, in piecing together this research, we are indebted to the late Mr. Akihiro Uemura at the Japan Bridge Association. We pray that his soul may rest in peace.

\section{REFERENCES}

1) Matsui, S.: Fatigue resistance of RC bridge deck under moving load and influence of water (In Japanese), Concrete Engineering Annual Collection of Papers, Vol. 9, No.2, pp.627-632, 1987.

2) Sakurai, N., Fujikawa, N., Mizukami, S., Matsui, S. and Nagai, M.: A study on rationalization of the shape steel bridge (In Japanese), JSCE Collected Works, No. 794/I-72, pp.67-86, 2005.

3) Kaidou, H., Watanabe, H., Tachibana, Y., Matsui, S. and Horikawa, T.: Evaluation for fatigue durability of overhanging part of steel plate-concrete composite deck by wheel trucking test and three-dimensional finite element analysis (In Japanese), Structure Engineering Collected Works, Vol.50A, pp.1119-1130, 2004.

4) National Institute for Land and Infrastructure Management Ministry of Land, Infrastructure and Transport: Research on Fatigue Durability Evaluation for Highway Bridge Slabs (In Japanese), Technical Notes of NILIM, No.472, August 2008.

5) Hawkins, M. N. and Mitchell, D.: Seismic response of composite shear connectors (In Japanese), Journal of Structural Engineering, ASCE, Vol.110, No.9, pp.2120-2136, 1984.

6) Matsui, S., Sasaki, H., Fukumoto, Y. and Kajikawa, S.: Fatigue of steel-concrete composite decks subjected to a moving wheel load (In Japanese), JSCE Committee of Structural Engineering, Vol.33A, pp. 409-420, 1988.

7) Fujiyama, C., Shang, F., Sakurai, N. and Maekawa, K.: Fatigue life simulation and failure mode for steel-concrete composite bridge deck based upon a direct path-integral scheme (In Japanese), JSCE Collected Works A, Vol. 66, No. 1, pp.106-116, 2010.3.

8) Fujiyama, C., Sakurai, N. and Maekawa, K.: Fatigue failure mode of steel-concrete composite bridge deck depending on interface property and shear connector profiles (In Japanese), JSCE Collected Works A, Vol. 67, No. 1, pp.193206, 2011.3.

9) Fujiyama, C., Sakurai, N. and Maekawa, K.: Failure mode of steel-concrete composite bridge deck depending on shear connector profiles (In Japanese), JSCE Collected Works A, Vol. 68, No. 1, pp.1-15, 2012.3.

10) Shima, H.: Effect of test method on load-slip relationships and axial behaviors of headed stud connector (In Japanese),
JSCE Collected Works A1 (Structural Engineering and Earthquake Engineering), Vol.67, No.2, pp.307-319, 2011.

11) Nakajima, A.: Shear connectors of steel-concrete composite structures (In Japanese), Collection of Lecture Summaries from the 9th Symposium on Compound Composite Structure Application, pp.S24-S28, 2011.

12) Ogiyama, Y., Fujiyama, C., Matsumura, T. and Takasuka, A.: Fatigue analysis of steel-concrete composite deck supported by plate girders (In Japanese), JSCE 68th Annual Academic Summary of Lectures, I-429, pp.857-858, 2013.

13) Maekawa, K., Pimanmas, A. and Okamura, H.: Nonlinear Mechanics of Reinforced Concrete (In Japanese), Spon Press, 2003.

14) Kurata, Y., Suzuki, O., Tachibana, Y., Kobayashi, K. and Inoue, A.: Study of modeling of steel-concrete composite deck for numerical analysis (In Japanese), 5th Highway Bridge Slab Symposium Collection of Papers, pp.199-204, 2006.

15) Rabbat, B. G. and Russell, H. G.: Friction Coefficient of Steel on Concrete or Grout (In Japanese), Journal of Structural Engineering, Vol.111, No.3, pp.505-515, 1985.

16) Maekawa, K., Toongoenthong, K., Gebreyouhannes, E. and Kishi, T.: Direct path-integral scheme for fatigue simulation of reinforced concrete in shear (In Japanese), Journal of Advanced Concrete Technology, Vol.4, No.1, pp.159-177, 2006.

17) Maekawa, K., Gebreyouhannes, E., Mishima, T. and An, X.: Three-dimensional fatigue simulation of RC slabs under traveling wheel-type loads (In Japanese), Journal of Advanced Concrete Technology, Vol.4, No.3, pp.445-457, 2006.

18) Nakajima, A., Inomata, Y., Saikawa, I. and Ooe, K.: Experimental study on static and fatigue shearing behavior between steel and concrete with bonding and mechanical action (In Japanese), JSCE Collected Works A, Vol.63, No.4, pp.758-767, 2007.

19) Anabuki, T., Gotou, Y. and Shiro, O.: Nonlinear finite element analysis on shear stress distribution in SRC bean-column joints (In Japanese), Proceedings of the Japan Concrete Institute, Vol.27, No.2, pp.403-408, 2005.

20) Architectural Institute of Japan: Mechanism of stress transferring and load resistance of structural joint made by steel and concrete (In Japanese), 2011.

21) Maekawa, K., Fukuura, N. and Soltani, M.: Path-dependent high cycle fatigue modeling of joint interfaces in structural concrete, Journal of Advanced Concrete Technology (In Japanese), Vol.6, No.1, pp.227-242, 2008.

22) Japan Society of Civil Engineers Committee on Hybrid Structure : 2009 Enacted Compound Structure Standards and Specifications (In Japanese), 2009.

23) Ooguchi, S., Sakai, T., Kubo, N., Umehara, I., Kimura, J. and Nakajima, A.: Comparison of shear-slip relations considering detail structures of different types of shear connectors (In Japanese), Collection of Lecture Summaries from the 9th Symposium on Compound Composite Structure Application, pp. 76-84, 2009.

(Received December 9, 2014) 